Original Article

\title{
DEVELOPMENT OF ANTI-WRINKLE CREAM FROM PUERARIA CANDOLLEI VAR. MIRIFICA (AIRY SHAW AND SUVAT.) NIYOMDHAM, “KWAO KRUA KAO” FOR MENOPAUSAL WOMEN
}

\author{
PANEE SIRISA-ARD ${ }^{1 *}$, NICHAKAN PEERAKAM ${ }^{1,2}$, NGUYEN QUOC HUY 3 , TRAN VAN ON ${ }^{3}$, PHUNG TUAN LONG ${ }^{4}$, \\ AEKKHALUCK INTHARUKSA ${ }^{1}$
}

${ }^{1}$ Faculty of Pharmacy, Chiang Mai University, Chiang Mai 50200, Thailand, ${ }^{2}$ Faculty of Pharmaceutical Sciences, Burapha University,

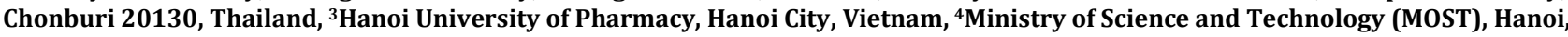
Vietnam

Email: pmpti008@gmail.com

Received: 07 Jan 2018 Revised and Accepted: 01 Jun 2018

\section{ABSTRACT}

Objective: The aim of this study was to incorporate Peraria candollei var. mirifica extract into the cream, to evaluate the physical properties and to conduct the skin tests in participants.

Methods: Pueraria candollei var. mirifica was extracted with 95\% ethanol to obtain crude pueraria extract (PCM). Crude PCM was developed as an anti-wrinkle PCM cream (B) intended for menopausal women. PCM cream was evaluated for stability of pH and viscosity, primary skin irritation, wrinkle reduction and moisturizing as well as customer satisfaction. Cream base (A) and cream purchased from the market (C) were used for comparison. ANOVA post hoc Turkey was used to analyze the variance $(\mathrm{p}<0.05)$ of the mean comparisons between groups by cluster analysis.

Results: The PCM cream appeared as white color, $\mathrm{pH}$ was 6.80 , and viscosity was $4.069 \pm 0.01 \mathrm{~Pa}$. s, as well as physical characteristic and texture, were acceptable and no irritating reaction. PCM cream exhibited a similar level of moisturizer as cream A and C. The PCM cream revealed an ability to decrease the wrinkle surface and wrinkle volume after applied for 7 and $14 \mathrm{~d}$ that shows the activity of this product performed from the PCM extract. Satisfaction of PCM cream showed good acceptance.

Conclusion: These results suggest that PCM cream has the ability to reduce skin wrinkles. It is a good product for postmenopausal women and may also be of benefit for the general population for protection skin wrinkle.

Keywords: Peraria candollei var. mirifica, Anti-skin wrinkle cream, Menopausal woman

(c) 2018 The Authors. Published by Innovare Academic Sciences Pvt Ltd. This is an open access article under the CC BY license (http://creativecommons.org/licenses/by/4.0/) DOI: http://dx.doi.org/10.22159/ijpps.2018v10i7.24665

\section{INTRODUCTION}

As is well-known, skin wrinkling is a problem for women. It has become obvious especially on women going through the period of menopause. In Thailand, one of the medicinal plants that have been used for treating this symptom is called KwaoKrua Kao well known as Pueraria candollei var. mirifica (PCM). The tuberous root of this plant was used as a local remedy for menopause-related vasomotor symptoms for centuries [1]. Suntara [2] mentioned PCM in a pamphlet written as a source of rejuvenation and good health and also stated PCM acted as the "Fountain of youth" for aged men and women when used for anti-skin wrinkle, an increase of hair growth and recovered black hair, to help with memory loss etc. [2], all of these functions probably related that PCM is the folk medicine that contained the substances of female hormone [3]. Much research determined the active compounds from PCM and reported that phytoestrogens such as miroestrol, deoxymiroestrol and isomiroestrol as well as the isoflavonoids comprised pureraria, daidzin, genistin, daidzein and genistein, etc. contained in this plant $[4-6,16]$. These compounds were tested for biological activities in many studies. The results found that miroestrol was produced from the oxidation of deoxymiroestrol [5] and both compounds showed an activity of estrogenic properties in ovariectomized rats [7] and also performed to enhance the effects of toremifene on MCF-7 human breast cancer cells [5]. Furthermore, miroestrol and deoxymiroestrol presented potentiality similar with estradiol [8-9] and both compounds are highly active phytoestrogens [10]. For the isoflavonoids, puerarin and daidzein showed the same level of antioxidant activity with $\alpha$-tocopherol [11] and the isoflavone, genistein, and daidzein (isolated from soybean) showed stronger antioxidant activity than isoflavone glycosides, daidzin and genistin [12]. However, the isoflavonoids were reported as the major components of PCM [13] and the amount of these compounds related to factors such as sub-species, cultivation area, harvesting period, etc. [14]. Therefore the number of active ingredients in PCM was recommended to use as standardization for crude PCM extract [1] before the development of the products. Moreover, PCM was developed into products for skin such as breast creams, eye gel, body gel, day and night cream and cataplasm/patches [15-16].

Some research reported that the skin moisture levels were improved by $39 \%$ after $24 \mathrm{~h}$ and retained $26 \%$ improvement after $3 \mathrm{w}$ when tested with ABS Pueraira mirifica extract PF compared with the untreated control and also showed moisturization 37\% better after $24 \mathrm{hr}$ and $7 \%$ better after $3 \mathrm{w}$ when compared with the base cream [17]. Suwanvesh et al. (2017) examined the effect of PCM gel on vaginal health in postmenopausal women for 12-weeks of treatment and found that PCM gel showed to be efficacy and safety for the treatment of vulvovaginal atrophy [18]. Our previous research focused on determining the quantity of phytoestrogen compounds and the isoflavonoids as standardization for crude extracts before the development of the products. The study discovered that crude extract of PCM obtained from 95\% ethanol extraction showed the highest quantity of phytoestrogens and isoflavonoids [unpublished]. Therefore the aim of this study was to develop the PCM as an antiwrinkle PCM cream for postmenopausal women.

\section{MATERIALS AND METHODS}

\section{Plant material and chemicals}

Tuberous root of PCM was collected from a controlled farm in Nakhon Prathom Province, Thailand. Voucher specimen No. CMU023231 was identified and kept at Herbarium of Faculty of Pharmacy, Chiang Mai University, Thailand. Chemical ingredients and solvent used for preparation the PCM cream are pharmaceutical grade were purchased from Union Sciences Co. Ltd., Thailand. 


\section{Plant extraction}

PCM tuberous root was cleaned and sliced by an automatic machine. Then the sample was dried in an oven at the temperature $60^{\circ} \mathrm{C}$ and ground to a powder. The sample powders were extracted with $95 \%$ of ethanol for $7 \mathrm{~d}$. The extractive sample was dried under reduced pressure by using an evaporator to obtain the PCM crude extract.

\section{Physiochemical properties of the crude extract}

PCM extract has tested the solubility and an incompatibility. The different solvents used during the experiment were $95 \%$ ethanol, water, propylene glycol, glycerin, $10 \%(\mathrm{w} / \mathrm{v})$ tween $80^{\circledR}$ in distilled water, $10 \%(\mathrm{w} / \mathrm{v})$ tween $20^{\circledR}$ in distilled water and PEG 40 castor oil $^{\circledR}$ and PEG $400^{\circledR}$ in three ratios are $1 \mathrm{mg}: 1 \mathrm{mg}, 1 \mathrm{mg}: 10 \mathrm{mg}$ and 1 $\mathrm{mg}: 100 \mathrm{mg}$. All of the data were used to design cream bases. The appropriate cream base was selected for further formulation.

\section{Development of anti-wrinkle PCM cream}

\section{Cream base preparation}

Four creambases were developed from the various composition by the conventional hot process. In the oil phase,such as cetyl alcohol, stearic acid, dimethicone, isopropyl palmitate, jojoba oil, ceteareth25, silicone oil, glyceryl monostearate, stearyl alcohol, squalene, cyclomethicone, myristic acid, mineral oil, isopropyl myristate, cetearyl alcohol, were mixed and heated on water bath at $70{ }^{\circ} \mathrm{C}$, while glycerin, sorbitol, triethanolamine, carbopol $940^{\circledR}$, sorbitol, propylene glycol, triethanolamine, as a water phase, these were then mixed on the water bath until the temperature was $55^{\circ} \mathrm{C}$, then the vitamin E acetate, sodium polyacryloyldimethyltaurate, hydrogenated polydeceneand trideceth 10 , phenoxy ethanol. The preparations were determined for their physical properties, $\mathrm{pH}$, spreadability and feel on the skin. The stability was tested in various conditions; room temperature, $4^{\circ} \mathrm{C}, 45^{\circ} \mathrm{C}$ for 1 mo and 6 cycles of heating/cooling conditions $\left(45^{\circ} \mathrm{C}, 24 \mathrm{~h}\right.$ alteration with $4{ }^{\circ} \mathrm{C} 24 \mathrm{~h}$ for 1 cycle). The most stable cream base was then selected to incorporate with the PCM extract. to be an anti-wrinkle cream.

\section{Formulation of anti-wrinkle PCM cream}

Crude PCM extract was combined with the selected cream base. The formulation was prepared with $0.6 \%(\mathrm{w} / \mathrm{w})$ of the PCM extract. After that, the PCM cream was evaluated for its physical appearance, phase separation, $\mathrm{pH}$ and viscosity.

\section{Stability test}

The PCM cream was tested to determine the stability of $\mathrm{pH}$ and viscosity ( $\mathrm{Pa} . \mathrm{s}$ ) under several conditions such as room temperature, $4^{\circ} \mathrm{C}$ and $45^{\circ} \mathrm{C}$ for 2 mo as well as 6 cycles of heating/cooling (h\&c) is $45^{\circ} \mathrm{C}$ for $24 \mathrm{~h}$. alternate with $4^{\circ} \mathrm{C}$ for $24 \mathrm{~h}$. was one cycle. Their physical changes were also immediately observed. The standard deviation was used to calculate in all data.

\section{Primary skin irritation test}

Primary skin irritation test using Finn chamber, which is the Draize model has been modified from Bashir and Maibach [19], tested with 9 participants. One gram of PCM cream was filled in the Finn chamber and placed on the back below the shoulder of the participants and covered with a thin plastic tape for $24 \mathrm{hr}$. Cream base and cream purchased from the market were used for comparison. Skin irritation was observed at $24 \mathrm{~h}, 48 \mathrm{~h}$ and $7 \mathrm{~d}$ after removal of the thin plastic tape. The area of testing was cleaned with warm water and left to dry. The draize scoring system was used to calculate the primary dermal irritation index (PDII).

Grading for the wheal flare and red response of the skin as follow:

$0=$ no wheal, flare and red

1 = very little wheal, flare and red

$2=$ visible wheal, flare and red

$3=$ massive wheal, flare and red

4 = very severe wheal, flare and red

\section{Skin wrinkle and moisture test}

Forty-five and sixty-year-old healthy women, 6 participants and no history of allergy to herbal compounds were selected to be participants for studies under approved by Ethical Review Committee, Faculty of Pharmacy Chiang Mai University, and identification No. 39/2016. The participants were informed of the details of the study. Cream base and creams purchased from the market were used for comparison. Cutometer MPA580 Germany was used to measure the moisture of the skin, and Visiometer SV 600 FW $\square$ Germany with probe VDO Sensor, CCD-Camera $640 \times 480$ pixel detect with a computer was used to evaluate the wrinkle of the skin.

\section{Satisfaction test}

The participants were given 0.5 grams of anti-wrinkle PCM cream to apply on their arms. Then satisfaction was evaluated in general on the physical properties of the product such as color, smell, texture, viscosity, and satisfaction on the use and also moistening on the skin, the sensation of touch, spreadability, absorbability, oiliness, greasiness, covering property as well as total satisfaction.

\section{Statistical analysis}

ANOVA post hoc Tukey Test was used to analyze the variance $(p<0.05)$ of the mean comparisons between groups by cluster analysis. The results were processed by a computer program: Excel and SPPSS version 19.0. The $\mathrm{pH}$ and the viscosity value were expressed as means \pm SD.

\section{RESULTS AND DISCUSSION}

\section{The solubility of PCM extract}

Crude PCM extract was tested for solubility and incompatibility with various vehicles. The results showed that PCM extract was soluble in $95 \%(\mathrm{w} / \mathrm{v})$ ethanol, water, propylene glycol, glycerin and $10 \%(\mathrm{w} / \mathrm{v})$ tween $80^{\circledR}$ in distilled water as well as $10 \%(\mathrm{w} / \mathrm{v})$ tween $20^{\circledR}$ in distilled water. Whereas this crude extract exhibited partial solubility in PEG $400^{\circledR}$ and insolubility in PEG 40 castor oil ${ }^{\circledR}$. This means that the PCM extract would prefer a hydrophilic environment rather than lipophilic, with the aid of the nonionic surfactants, polyoxyethylene-sorbitan monolaurate, tween $20^{\circledR}$ (HLB 16.7) and polyoxyethylene sorbitan monolaurate, tween $80^{\circledR}$ (HLB 15.0). The data obtained was used in the pre-formulation of the PCM cream. All results were shown in table 1.

Table 1: Solubility and compatibility of PCM extract in various vehicles

\begin{tabular}{|c|c|c|c|}
\hline \multirow[t]{2}{*}{ Vehicle } & \multicolumn{3}{|c|}{ Observation the ratio of PCM solubility } \\
\hline & $1: 1$ (mg/mg) & $1: 10(\mathrm{mg} / \mathrm{mg})$ & $1: 100(\mathrm{mg} / \mathrm{mg})$ \\
\hline 95\% ethanol & soluble & soluble & soluble \\
\hline distilled water & soluble & soluble & soluble \\
\hline propylene glycol & soluble & soluble & soluble \\
\hline glycerin & soluble & soluble & soluble \\
\hline PEG 40 castor oil ${ }^{\circledR}$ & insoluble & insoluble & insoluble \\
\hline PEG $400^{\circledR}$ & partial soluble & partial soluble & partial soluble \\
\hline $10 \%$ tween $80^{\circledR}$ in distilled water & soluble & soluble & soluble \\
\hline $10 \%$ tween $20^{\circledR}$ in distilled water & soluble & soluble & soluble \\
\hline
\end{tabular}




\section{Stability test}

The product appeared as a white cream with acceptable physical characteristics as well as consistency in texture, viscosity $(4.069 \pm 0.01 \mathrm{~Pa}$. s) and $\mathrm{pH} 6.82 \pm 0$. The results of stability tests at the accelerate conditions of $4^{\circ} \mathrm{C}, 45^{\circ} \mathrm{C}$ and room temperature $\left(25^{\circ} \mathrm{C}\right.$ $30^{\circ} \mathrm{C} \pm 2^{\circ} \mathrm{C}$ ) showed that there were no changes to physical properties of the cream in terms of $\mathrm{pH}$, the phase of separation and color, although there was slightly changed in viscosity. Nevertheless the overall evaluation, the PCM cream demonstrated the potential for a prototype product leading to the large-scale production of antiwrinkles cosmetic, however, the long-term stability test should be performed in order to predict its shelf life. The results of $\mathrm{pH}$ and viscosity stabilities tests are shown in table 2.

Table 2: pH and viscosity stabilities of the PCM cream

\begin{tabular}{lllllll}
\hline Conditions & $\mathbf{p H}^{\mathbf{a}}$ & \multicolumn{3}{c}{ Viscosity (Pa. s) $^{\mathbf{b}}$} \\
\cline { 2 - 6 } & $\mathbf{A f t e r}$ preparation & $\mathbf{1 ~ m o}$ & $\mathbf{2 ~ m o}$ & After preparation & $\mathbf{1}$ mo & $\mathbf{2 ~ m o}$ \\
\hline $4^{\circ} \mathrm{C}$ & $6.82 \pm 0$ & $6.77 \pm 0.006$ & $6.81 \pm 0.010$ & $4.069 \pm 0.011$ & $3.925 \pm 0.002$ & $2.836 \pm 0.005$ \\
$45^{\circ} \mathrm{C}$ & $6.82 \pm 0$ & $6.85 \pm 0.006$ & $6.58 \pm 0$ & $4.069 \pm 0.011$ & $3.873 \pm 0.003$ & $5.824 \pm 0.003$ \\
$\mathrm{rt}$ & $6.82 \pm 0$ & $6.77 \pm 0.006$ & $6.80 \pm 0.010$ & $4.069 \pm 0.011$ & $3.622 \pm 0.003$ & $2.342 \pm 0.004$ \\
handc & $6.82 \pm 0$ & $6.71 \pm 0.006$ & - & $4.069 \pm 0.011$ & $3.747 \pm 0.003$ & - \\
\hline
\end{tabular}

rt: room temperature $\left(25^{\circ} \mathrm{C}-30^{\circ} \mathrm{C} \pm 2^{\circ} \mathrm{C}\right)$, handc: heating and cooling condition $\left(45^{\circ} \mathrm{C} 24 \mathrm{~h}\right.$ alteration with $4^{\circ} \mathrm{C} 24 \mathrm{~h}$ for 1 cycle) continuing for 6 cycles, a,b: mean \pm SD, $n=3$

\section{Primary skin irritation test}

The safety of the PCM cream was evaluated from the determination of irritation test compared with the cream base and cream purchased from the market. The 30 participants were observed after applied their creams. The result showed that all participants had no irritating reaction with all creams as shown in table 3.

Table 3: The irritation scoring of PCM cream compared with a cream base and cream purchased from market

\begin{tabular}{lll}
\hline Sample & \multicolumn{2}{l}{ Average score of the irritating reaction* } \\
\cline { 2 - 3 } & $\mathbf{2 4 h} \mathbf{4 8 ~ h}$ & $\mathbf{7} \mathbf{d}$ \\
\hline Cream base (A) & 0 & 0 \\
The anti-wrinkle PCM cream (B) & 0 & 0 \\
Cream purchase from market (C) & 0 & 0 \\
\hline
\end{tabular}

*performed in 9 participants

\section{Skin wrinkle and moisture test}

The skin wrinkle and moisture tests of the PCM cream were evaluated and compared with the cream base and cream purchased from the market. The skin moisture test was determined in term of hydration of the skin. The wrinkle was observed on the wrinkled surface, which calculated the size of the "wavy" surface in comparison to the stretched surface, as well as wrinkle volume, which calculated the virtual amount of liquid needed in the calculation area to fill the image until the average height of all peaks. All data obtained by Visioscan evaluation from participants after application of all sample creams for 0,7 and $14 \mathrm{~d}$.

The skin moisture test showed that after application of cream base (A), PCM cream (B) and cream purchased from the market
(C) no significant change of the hydration of the skin in all participants $(p \square<0.05)$. The trend of the skin moisture after application of PCM cream exhibited a bit higher when compared with cream base in six participants (GO, MP, PJ, PC, MW and JP) and also showed equal to cream base one participant (PN) and showed a bit lower than cream base with two participants (LC and LY). When compared with cream C, the moisture of PCM cream presented slightly lower than cream $\mathrm{C}$ in six participants (GO, MP, PC, MW, LC, and JP) and exhibited a little bit higher than cream $\mathrm{C}$ in three participants (PJ, PN, and LY) (fig. 1). The result of the skin moisture test may change from a higher level of PCM extract. More amount of PCM crude extract may give greater moisturizer.

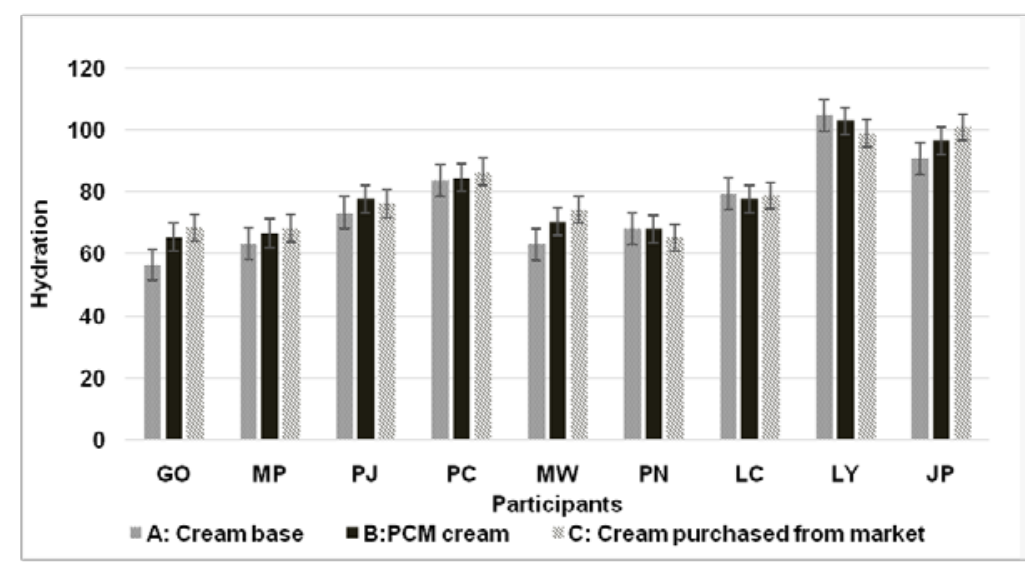

Fig. 1: The skin hydration after applied cream A, B and C for 14 d, GO, MP, PJ, PC, MW, PN, LC, LY and JP were names of the nine participants in the study 
Considering the wrinkle test, cream B showed the ability to reduce wrinkles. The result of wrinkle surface diminished after using PCM cream in all participants. The value of wrinkle surfaces tends to subside after 7 and $14 \mathrm{~d}$ as the results shown in fig. 2. Interestingly after applying PCM cream for $14 \mathrm{~d}$, the wrinkle volume obviously decreased in all participants. The PCM cream presented significant $(\mathrm{p}<0.05)$ subsidence of wrinkle volume when comparing day 0 and day 14 (fig. 3). This result can be summarized, that PCM cream has the capability to reduce wrinkle. After the application for 7 and $14 \mathrm{~d}$, the wrinkles will decrease. This product would help to improve the appearance of skin after continuous use. The main ingredient that gave this activity is PCM extract. The effect of this plant can slow down and retard wrinkles (fig. 4). Appearance of skin in $14 \mathrm{~d}$, PCM cream (B) clearly demonstrated slightly shallowing of a wrinkle in the skin treated with PCM cream which contained $0.6 \%(\mathrm{w} / \mathrm{w})$ of PCM extract, lesser wrinkle than the cream base (A) and cream purchased from the market (C). The previous research demonstrated that applying 6\% Pueraria mirifica vaginal gel improved symptoms of vulvovaginal atrophy, restored vaginal epithelium in a similar fashion to the oral administered form [18]. Moreover, Pueraria mirifica extract was used to test the topical vaginal treatment in postmenopausal monkeys, the result proved that Pueraria mirifica extract could stimulate the maturation of the vaginal epithelium without causing systemic side effects [20]. These results confirmed the folk wisdom of the native people in Thailand that used and mentioned Pueraria as the source of rejuvenation [2]. Our study confirmed that the PCM cream can improve wrinkle skin after treatment with $0.5 \mathrm{gm}$ of $0.6 \%(\mathrm{w} / \mathrm{w})$ of the PCM cream in $7 \mathrm{~d}$ by the main bioactive agents in PCM extract which were miroestrol and deoxymiroestrol, possess phytoestrogenic activity. These observations also revealed that the benefit of the PCM extract might be increased if the percentage of PCM extract were higher than $0.6 \%(\mathrm{w} / \mathrm{w})$ in which safety should be cautioned.

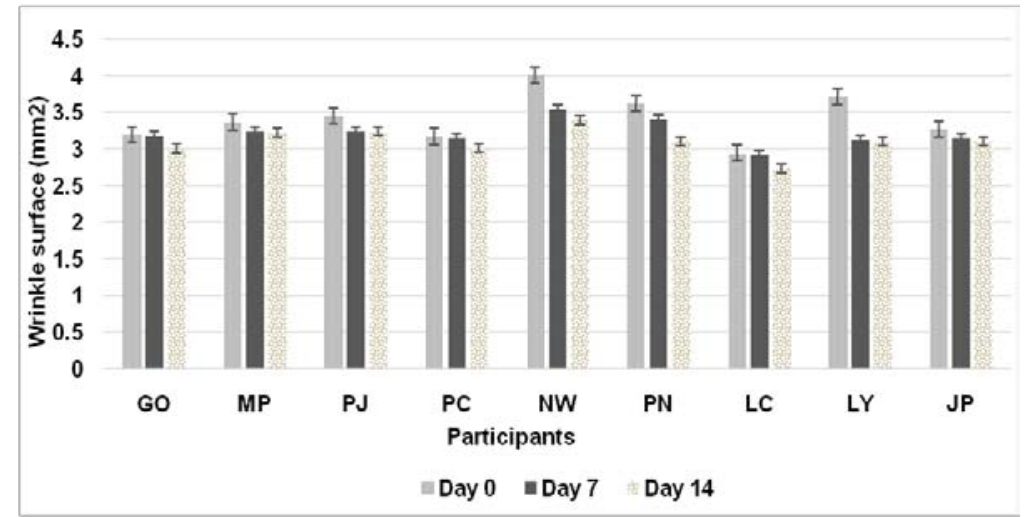

Fig. 2: Wrinkle surface after tested with the anti-wrinkle PCM cream for 0,7 and 14 d, GO, MP, PJ, PC, MW, PN, LC, LY and JP were the names of participants in the study

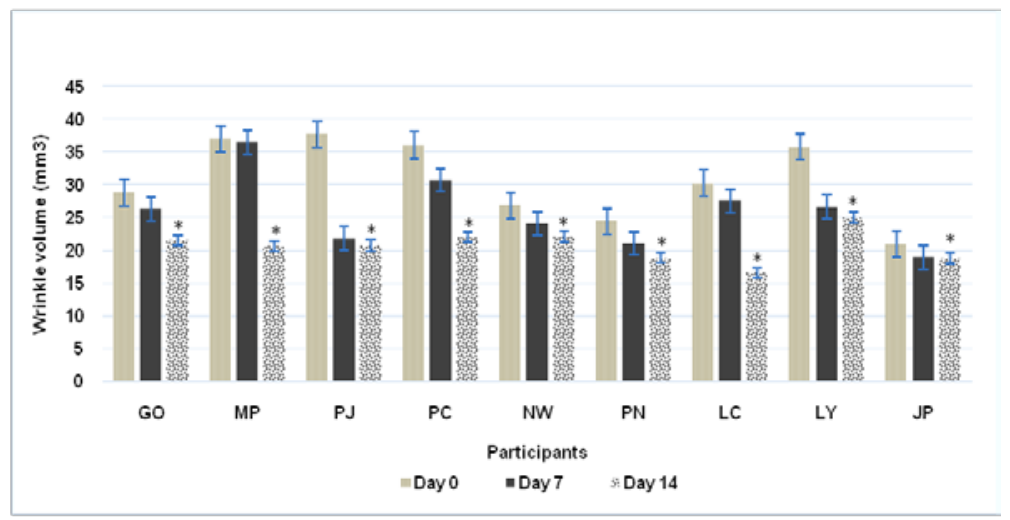

Fig. 3: Wrinkle volume after testing with the anti-wrinkle PCM cream for 0,7 and $14 \mathrm{~d}$, *significant ( $<<0.05)$ day 0 compared with day 14 , GO, MP, PJ, PC, MW, PN, LC, LY and JP were the names of nine participants in the study

A:

cream base
Day 0

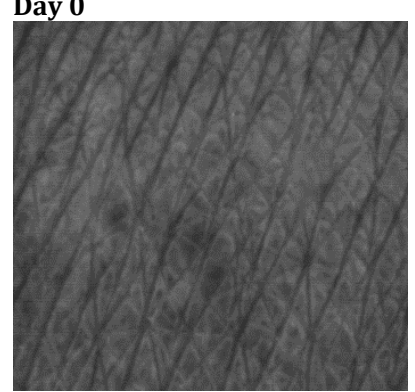

Day 7

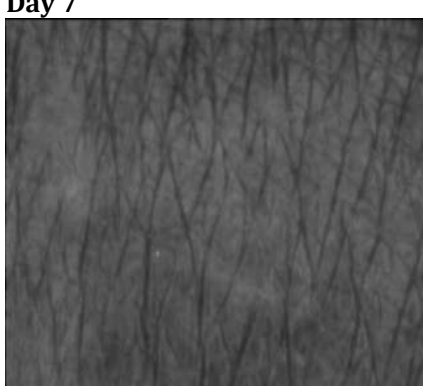

Day 14

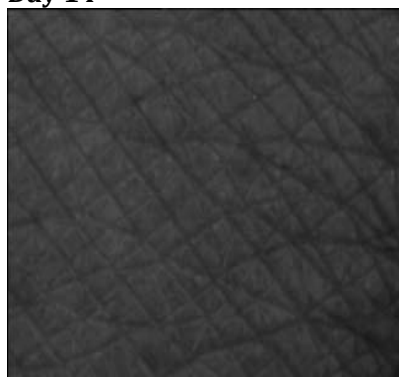


B:

PCM cream

C: cream purchased from market
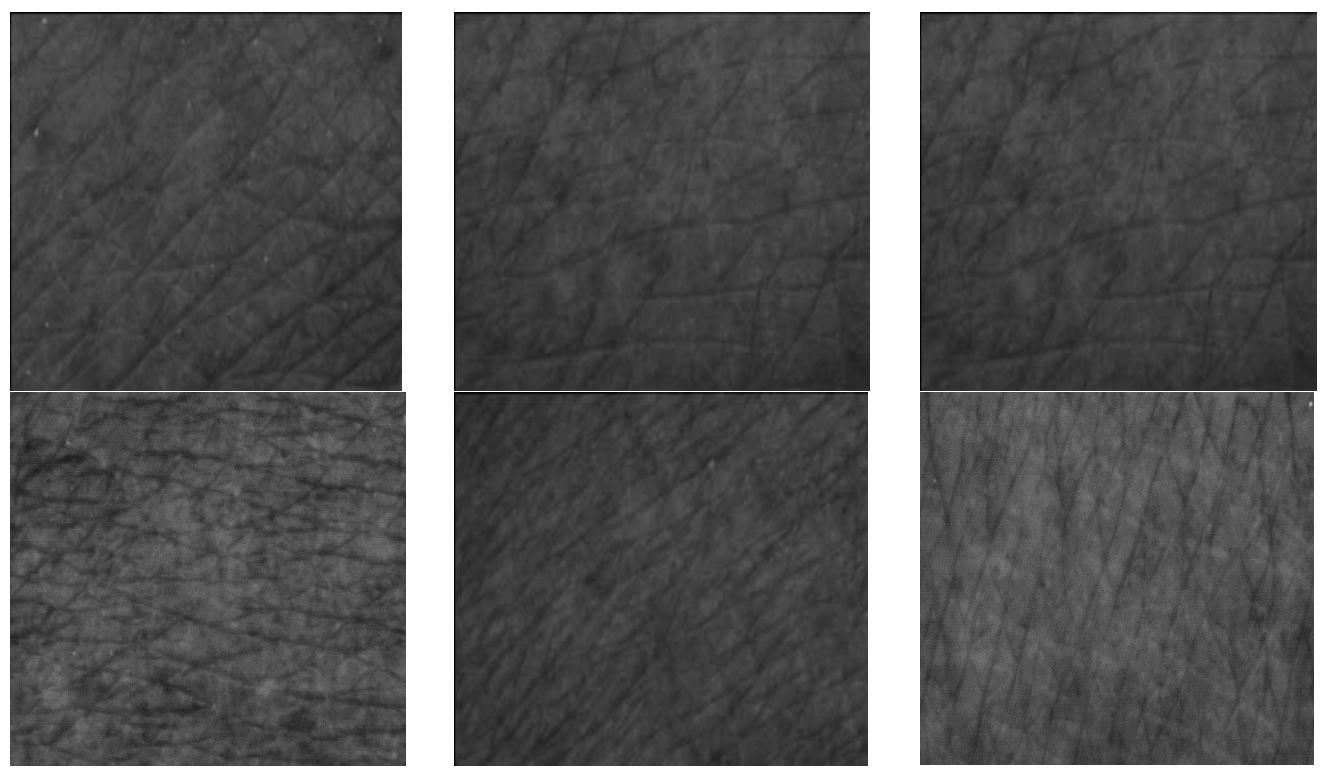

Fig. 4: Comparative wrinkle skins after testing with several creams in $14 \mathrm{~d}$

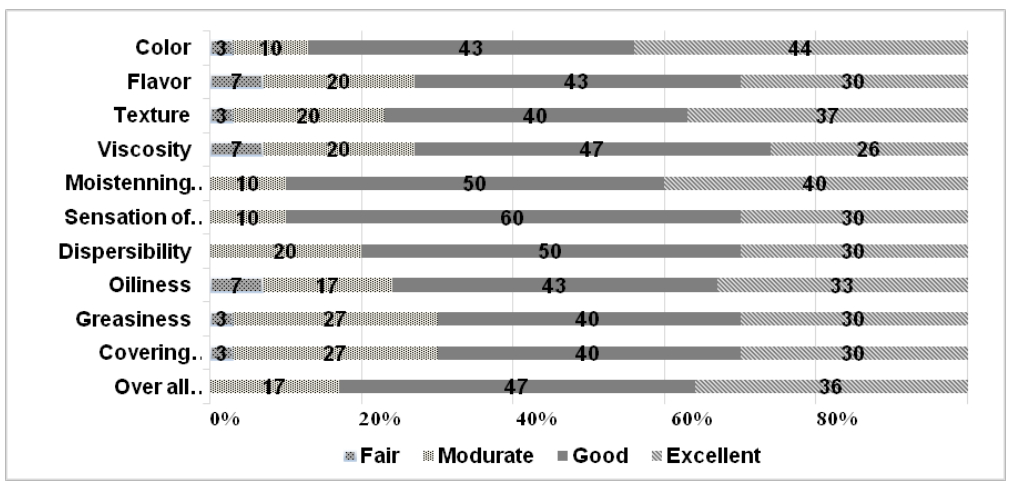

Fig. 5: Satisfaction and general feature of PCM cream in 30 participants

\section{Satisfaction test}

Evaluation of general satisfaction of PCM cream in 30 volunteers. The result exhibited that the majority of participants were well satisfied with the product. Thirty to forty gave excellently, $8-27 \%$ gave with moderate and $3-7 \%$ gave fair. In summary, PCM cream showed good to excellent result in the grading of satisfaction as in fig. 5 .

\section{CONCLUSION}

This information concluded that the anti-wrinkle PCM cream revealed ability decreases wrinkle surface and wrinkle volume after applied for 7 and $14 \mathrm{~d}$. This product even no high moisturizer but it showed obviously ability to reduce skin wrinkle. The continuous using PCM cream would help to retard and slow down the wrinkle. The satisfaction of PCM cream is good to excellent which exhibited the acceptable of the user. Therefore PCM cream is a good product for postmenopausal women and may also for the general lady that need to protect skin wrinkle. Moreover, the product obtained for this research would be a commercial benefit in our country as well as to be utilization the resource of the country to be high potentiality.

\section{ACKNOWLEDGEMENT}

The authors wish to express our thanks to the ASEAN+3 CrossBorder Research Project Awarded by International College of Digital Innovation Chiang Mai University for grant support and also special thanks to Kovic Kate International Co., Ltd. for analytical laboratory support.

\section{AUTHORS CONTRIBUTIONS}

Panee Sirisa-ard and Aekkhaluck Intharuksa have performed experimentation work and data collection. Nichakan Peerakam has drafted the manuscript. Nguyen Quoc Huy, Tran Van On and Phung Tuan Long have studied the method of the raw material control.

\section{CONFLICT OF INTERESTS}

There are no conflicts of interest to declare

\section{REFERENCES}

1. FDA. Origin and description of Pueraria mififica. Available from: http://www.fda.gov/ohrms/dockets/dockets/95s0316/95s0316-rpt0224-13-Tab-II-Origin-and-Description-of-PuerariaMirifica-vol162.pdf [Last accessed 10 Oct 2015]

2. Suntara A. The remedy pamphlet of kwao krua tuber of laung anusarnsuntara-kromarnphiset. Chiang Mai, Thailand: Chiang Mai Upatipongsa Press; 1931.

3. Pope GS, Grundy HM, Jones HEH, Tait SAS. The estrogenic substance (miroestrol) from the tuberous roots of Pueraria mirifica. J Endocrinol 1958;17:15-6.

4. Tayler NE, Hodgkin DC, Rollett JS. The X-ray crystallographic determination of the structure of bromomiroestrol. J Chem Soc 1960;33:3685.

5. Chansakaow S, Isikawa $T$, Seki $H$, Sekine $K$, Okada $M$, Chaichantipyuth C. Identification of deoxymiroestrol as the actual rejuvenating principle of "Kwao Keur," Pueraria mirifica. The known miroestrol may be an artifact. J Nat Prod 2000a;63:173-5. 
6. Chansakaow S, Ishikawa T, Sekine K, Okada M, Higuchi Y, Kudo $\mathrm{M}$, et al. Isoflavonoids from Puerariamirifica and their estrogenic activity. Planta Med 2000b;66:572-5.

7. Benson GK, Cowie AT, Hosking ZD. Mammogenic activity of miroestrol. J Endocrinol 1961;21:401.

8. Udomsak L, Juengwatanatrakul T, Putalun W, Jarukamjorn K. Biomodal action of miroestrol and deoxymiroestrol, phytoestrogens from Pueraria candollei var. mirifica on hepatic CYP2B9 and CYP1A2 expressions and anti-lipid peroxidation in mice. Nutr Res 2012;32:45-51.

9. Udomsak L, Juengwatanatrakul T, Putalun W, Jarukamjorn K. Suppression of BSEP and MRP2 in mouse liver by miroestrol and deoxymiroestrol isolated from Puerariacandollei. Phytomedicine 2012;19:1332-5.

10. Udomsuk L, Juengwattanatrakul T, Jarukamjorn K, Putalun W. Increased miroestrol, deoxymiroestrol and isoflavonoid accumulation in callus and cell suspension cultures of Pueraria condollie var. mirifica. Acta Physiol Plant 2012;34:1093-100.

11. Cherdshewasart W, Sutjit W. Correlation of antioxidant activity and major isoflavonoid contents of the phytoestrogen-rich Pueraria mirifica and Pueraria lobate tubers. Phytomedicine 2008;15:38-43.

12. Lee $\mathrm{CH}$, Yang L, Xu JZ, Yeung SYV, Haung Y, Chen ZY. Relative antioxidant activity of soybean isoflavones and their glycosides. Food Chem 2005;90:735-41.

13. Cherdshewasart W, Subtang S, Dahlan W. Major isoflavonoid contents of the phytoestrogen rich-herb Pueraria mirificain comparison with Pueraria lobate. J Pharm Biomed Anal 2007b;43:428-34.

14. Haferkamp MR. Environmental factors affecting plant productivity. Fort Keogh Research Symposium; 1987. p. 27-32.

15. Dweck AC. FLS FRSC FRSH. The Pueraria family with special in interest in Pueraria mirifica. Personal Care Magazine 2000;3:7-10.

16. Cherdshewasart W. Extraction derived from Pueraria mirifica, Butea Superba and/or Mucuna collettii and extraction thereof; 2004.

17. Active Concepts. ABS Puerari amirifica extracts PF efficacy data. Available from:http://activeconceptsllc.com/wp-content/ uploads2015/02Efficacy-Dock-Sheet2pdf. [Last accessed on 10 Dec 2018].

18. Suwanvesh N, Manonai J, Sophonsritsuk A, Cherdshewasart W. Comparison of Pueraria mirifica gel and conjugated equine estrogen cream effect on vaginal health in postmenopausal women. Menopeuse 2017;24:210-5.

19. Bashir SJ, Maibach HI. In vivo Irritation. In: Paye M, Barel AO Maibach HI. Eds. Handbook of Cosmetic Science and Technology. $2^{\text {nd }}$ Edn. Taylorand Francis Group, New York; 2001. p. 905-16.

20. Jaroenporn S, Urasopon N, Watanabe G, Malaivijitnond S. Improvements of vaginal atrophy without systemic side effects after topical application of Pueraria mirifica, a phytoestro-rich Herb, in postmenopausal cynomolgus macaques. J Repord Dev 2014;60:238-45. 